\title{
CONSTRUCIONALIZAÇÃo E MUDANÇA CONSTRUCIONAL DE LOCUÇÕES CONJUNTIVAS EM PORTUGUÊS: O CASO DE NA HORA QUE
}

\author{
Diego Minucelli Garcia \\ Gisele Cássia de Sousa
}

\section{RESUMO}

O objetivo deste trabalho é analisar as mudanças construcionais por que passam a locução conjuntiva ((n)a) hora (em) que do português. A abordagem teórica adotada é a da Gramática de Construções e de sua extensão ao estudo da mudança linguística proposta por Traugott e Trousdalle (2013). A partir dos resultados da análise dos graus de composicionalidade, produtividade e esquematicidade das construções extraídas de um banco de dados do português falado no interior paulista, propomos uma hierarquia construcional capaz de mapear a trajetória de construcionalização de na hora que e de locuções conjuntivas semelhantes. Essa hierarquia teria como construção mais esquemática a forma $\left[\mathrm{N}_{\text {Circunstancial }} \text { que }\right]_{\text {CONECTivo }}$.

Palavras-chave: mudança linguística, construcionalização, conjunção, conjunção temporal.

\section{ABSTRACT}

The aim of this paper is to analyze constructional changes of Portuguese conjunctive locution $n a$ hora em que (lit. at the hour in that). The theoretical approach adopted is the Construction Grammar

1 Este artigo é baseado na dissertação de Mestrado do primeiro autor, desenvolvida sob orientação da segunda autora.

2 Doutorando do Programa de Pós-graduação em Estudos Linguísticos da Universidade Estadual Paulista campus de São José do Rio Preto/SP. E-mail: diegominucelli@gmail.com.

3 Docente da Universidade Estadual Paulista - campus de São José do Rio Preto/SP. E-mail: giselecs@ibilce. unesp.br. 
and its extension to the study of linguistic change proposed in Traugott and Trousdalle (2013). From the results of the analysis of the degrees of compositionality, productivity and schematicity of the constructions extracted from a database of Portuguese spoken in the interior of São Paulo, we propose a constructional hierarchy capable of mapping the possible constructionalization trajectory of na hora que and similar conjunctive locutions. This hierarchy would have $\left[\mathrm{N}_{\text {Circunstancial }} \text { que }\right]_{\text {Conectivo }}$ as a more schematic construction.

Keywords: linguistic change, constructionalization, conjunctions, temporal conjunctions.

\section{Introdução}

Este trabalho focaliza a natureza formal e funcional de locuções conjuntivas formadas por [preposição em] + [artigo definido singular $(o, a)]+[$ substantivo indicativo de uma circunstância (temporal (hora, dia, momento), causal (causa, razão), proporcional (medida, proporção), etc.)] + [preposição em] + [pronome relativo que]. A forma na hora em que, exemplificada abaixo, é representativa dessas locuções em português e constitui o foco das análises realizadas neste trabalho. A forma na hora em que, exemplificada abaixo, é representativa dessas locuções em português e constitui o foco das análises realizadas neste trabalho. Os dados analisados são representativos do português falado na região noroeste do estado de São Paulo e integram o banco de dados IBORUNA. ${ }^{4}$

(1) geralmente dá quinze panquecas... doze a quinze panquecas... uma ao lado da o(u)tra como a gente gosta de fazê(r)... e coloco no forno com que(i)jo... derretê(r)... [Doc.: ai que ruim] e... meu marido gosta muito de queijo ralado então o dele tá sempre lá do lado como eu num gosto muito... na hora em que ele vai por o molho vermelho por cima ele já... joga o que(i)jo ralado... e é só comê(r) (IBORUNA-AC-080)

Conforme se observa a partir do exemplo (1), é possível interpretar a oração em que ele vai por o molho vermelho por cima, que segue o SPrep [na hora], como uma oração relativa cujo papel é especificar o nome temporal hora. Entretanto, mesmo que a oração com que seja assim interpretada, a oração inteira, encabeçada por na hora, indica uma localização temporal (na hora em que ele vai por o molho vermelho por cima) para o estado-de-coisas expresso na oração seguinte (ele já joga o queijo ralado), prevalecendo, assim, a instauração de um esquema hipotático temporal resultante das orações combinadas.

4 Informações mais detalhadas sobre o banco de dados IBORUNA e sua composição podem ser obtidas em http://www.iboruna.ibilce.unesp.br. 
Essa dupla possibilidade de interpretação, como também consideram Pereira, Braga e Paiva (2010), torna-se, entretanto, menos provável à medida que a sequência passa a ser empregada sob formas reduzidas, com apagamento dos elementos que circundam o nome temporal. As ocorrências a seguir, registradas no português falado, exemplificam essa redução de na hora em que, com apagamento: (i) da preposição em após o nome hora no exemplo em (2); (ii) da preposição em antes do nome hora no exemplo em (3), restando apenas o artigo a (hora); e (iii) por fim, apagamento também do artigo $a$ antes de hora no exemplo em (4), de que resulta a forma mais reduzida hora que.

(2) você pega a goiabada você derrete um pedaço dela... com um po(u)co de água... $\underline{n a}$ hora que ela fica bem cremosa dura... você pega esse creme branco e mistura com a... calda ... da goiabada (IBORUNA-AC-106)

(3) eu de(i)xei ele saí fui po banco... a hora que eu tava manobran(d)o...manobran(d)o o carro pra estacioná(r)... éh:: três pessoas... abriram a porta do meu carro... (IBORUNAAC-077)

(4) Ela arremessô(u) a faca eu num senti NADA $^{5}$ num doeu NADA NADA NADA... $\underline{\text { hora }}$ que eu vi tava jorran(d)o sangue... acho que POR DEUS que tinha uma toalha de banho (ela apertô(u)) (inint.) e (saímos) pro postinho (IBORUNA-AC-027)

Assim, consideramos neste artigo que, em sua forma mais completa, na hora em que funciona de dois modos: como uma locução conjuntiva que marca uma oração temporal em relação a uma oração subsequente (principal); e como um sintagma no qual um nome circunstancial temporal (hora) é especificado por uma oração relativa iniciada por (em) que. À medida que vão se apagando os elementos que antecedem e que seguem o nome hora, a função conjuncional da forma se torna sobressalente, e esmaece, consequentemente, a interpretação de uma especificação do nome hora por meio de uma oração relativa. Em outras palavras, com o apagamento de alguns de seus elementos, reduz-se a composicionalidade da forma, e a interpretação passa a ser a de ((n)a) hora (em) que como um só bloco, com função conjuncional semelhante à de uma conjunção como quando em português.

A interpretação não composicional de formas sequenciais é característica de construções, conforme a define, por exemplo, Goldberg (1995): “C é uma CONSTRUÇÃO se C for um pareamento de forma-significado $<\mathrm{F}_{\mathrm{i}}, \mathrm{S}_{\mathrm{i}}>$ de modo que algum aspecto de $\mathrm{F}_{\mathrm{i}}$ ou algum aspecto de $\mathrm{S}_{\mathrm{i}}$ não seja estritamente previsível a partir das partes componentes de C [...]”6 (GOLDBERG, 1995, p. 4).

5 No córpus analisado, a caixa-alta indica pronúncia com entonação elevada.

$6 \mathrm{C}$ is a CONSTRUCTION iffdef $\mathrm{C}$ is a form-meaning pair $<\mathrm{Fi}, \mathrm{Si}>$ such that some aspect of Fi or some aspect of $\mathrm{Si}$ is not strictly predictable from C's component parts [...] (GOLDBERG, 1995, p. 4). 
Assumimos, deste modo, que ((n)a) hora (em) que constitui uma construção com função conjuncional no português brasileiro contemporâneo e pretendemos, a partir daí, demonstrar aspectos de sua natureza formal e funcional, bem como descrever seu estatuto construcional em português. Mais especificamente, buscaremos descrever, com base nas propostas de Traugott (2008, 2012) e de Traugott e Trousdale (2013), em uma perspectiva sincrônica, os graus de esquematicidade, composicionalidade e produtividade da construção, em suas formas mais completas (na hora (em) que) e mais reduzidas (a hora que, hora que). A partir desses graus, propomos uma hierarquia construcional de ((n)a) hora (em) que, capaz de captar passos de sua mudança construcional e, possivelmente, seu processo de construcionalização.

A proposta deste trabalho alia-se, portanto, aos estudos de Gramática de Construções e ao modelo da Linguística Centrada no Uso, em franca expansão em países dos Estados Unidos, da Europa e também no Brasil (nesse último, citem-se, entre outros, Salomão (2002), Miranda e Salomão (2009), Furtado da Cunha (2013), Furtado da Cunha e Bispo (2013), Furtado da Cunha, Silva e Bispo (2016), Cezario e Furtado da Cunha (2013), Oliveira e Rosário (2015), Rosário e Oliveira (2016), Pinheiro e Ferrari (2015a, b), Fumaux, Alonso e Cezario (2017), Garcia (2017)). Desse modo, a partir dos objetivos aqui propostos, o trabalho, além de fomentar o desenvolvimento de estudos a respeito do português sob essas vertentes teóricas, também pode contribuir para as discussões acerca da validade do modelo de Gramática de Construções e das propostas de mudança construcional e construcionalização no tocante à descrição de diferentes estruturas linguísticas efetivamente empregadas na língua em uso.

Este texto encontra-se dividido em cinco seções. Após esta seção inicial, seguem-se considerações sobre a proposta de Traugott $(2008,2012)$ e de Traugott e Trousdale (2013) acerca da mudança construcional e da construcionalização, ao lado de reflexões sobre a relação entre esses processos e a gramaticalização, fenômeno mais antigo e conhecido nos estudos funcionalistas. Nas duas seções subsequentes, encontram-se as análises da natureza construcional de ((n)a) hora (em) que e a proposta de uma hierarquia que reflita seus graus de mudança construcional e de construcionalização. Encerram o texto, as conclusões do trabalho.

\section{Construcionalização e gramaticalização}

Grande parte das pesquisas atuais voltadas à descrição sintático-gramatical com base na 
abordagem cognitivo-funcional, ou na abordagem da Linguística Centrada no Uso, relaciona-se aos modelos de Gramática de Construções (CROFT, 2001, 2007; GOLDBERG, 1995, 2006) e se fundamentam na concepção de que a língua é um conjunto de construções, isto é, de pareamentos entre forma e função. A mudança linguística baseada nessa visão é vista como um processo que atinge a língua criando novas construções, ou alterando subcomponentes de uma construção (TRAUGOTT, TROUSDALE, 2013).

De acordo com Traugott e Trousdale (2013), a mudança linguística ocorre por meio de dois processos: a mudança construcional, quando não há a criação de nova construção, mas uma alteração de suas subpartes, e a construcionalização, quando efetivamente ocorre a criação de uma nova construção.

Nessa perspectiva, Traugott (2012) afirma que a mudança construcional afeta os subcomponentes de uma construção, isto é, seus fatores sintáticos, morfológicos, fonológicos, semânticos e pragmáticos. O processo de mudança construcional, ao atingir uma construção, não necessariamente afeta todos os seus subcomponentes ao mesmo tempo, o que indica que ele pode ocorrer em aspectos somente formais ou somente funcionais de uma construção.

Para exemplificar essa ocorrência da mudança em subcomponentes distintos de uma construção, Traugott (2012) descreve as mudanças construcionais por que passa a forma will do inglês. Em relação ao subcomponente semântico, will teria passado por uma mudança de sentido de ter intenção para codificador de futuro. Corroborando essa mudança, como demonstra a autora, no subcomponte sintático, will passou de verbo pleno (lexical) para verbo auxiliar (gramatical). No subcomponente morfofonológico, will se reduz a ' $l l$, aglutinando-se a pronomes pessoais ao codificar o futuro de verbos plenos (I'll wait for you).

Assim, conforme afirmam Traugott e Trousdale (2013), a "mudança construcional é uma mudança que afeta a dimensão interna de uma construção. Não envolve a criação de um novo nó" ${ }^{7}$ (p. 26). A construcionalização, por sua vez, de acordo com esses autores:

é a criação (combinação) de novos signos forma ${ }_{\text {nova }}$-significado ${ }_{\text {novo }}$. Ela forma novos tipos de nós, os quais têm nova sintaxe ou morfologia e novo significado codificado na rede linguística de uma população de falantes. É acompanhada por mudanças nos graus de esquematicidade, produtividade e composicionalidade. A construcionalização de esquemas sempre resulta de

7 A constructional change is a change affecting one internal dimension of a construction. It does not involve the creation of a new node (TRAUGOTT, TROUSDALE, 2013, p. 26). 
uma sucessão de micropassos e, portanto, é gradual. ${ }^{8}$ (TRAUGOTT, TROUSDALE, 2013, p. 21-22).

Em termos gerais, entende-se a esquematicidade como o aumento ou diminuição de abstração semântica e sintática da construção. A produtividade liga-se ao desenvolvimento de novos tipos de construção, em geral, por meio da extensão de padrões já existentes, ao passo que a composicionalidade diz respeito ao nível de acesso semântico (global ou individual) das subpartes das formas.

Considerando-se, pois, que a construcionalização é o processo pelo qual se descrevem as mudanças por que passam construções de uma língua, uma importante questão se coloca no âmbito dos estudos funcionalistas: em que medida a construcionalização se relaciona à gramaticalização, processo de mudança mais amplamente conhecido?

Esse questionamento, conforme aponta Silva (2012), deriva naturalmente de um contraste entre a concepção clássica de gramaticalização, entendida, desde Meillet (1948a, b) como mudança unidirecional que transforma um item (menos) lexical em (mais) gramatical (HOPPER; TRAUGOTT, 1993), e os avanços dos estudos descritivos e das perspectivas teóricas orientadas pelo uso linguístico.

Conforme demonstra Silva (2012), com o desenvolvimento dos estudos cognitivistas e funcionalistas, e de modelos baseados no uso, como a Gramática de Construções, as mudanças descritas passaram a envolver não necessariamente apenas itens lexicais ou gramaticais, mas também construções em contextos específicos de uso. Em vez de se dissociarem por completo, construcionalização e gramaticalização, assim, podem ser vistas em uma relação de complementação, visando abranger, sem exceção, as diferentes formas de uma língua, de morfemas a expressões idiomáticas ou estruturas ainda mais esquemáticas, como a ordem de palavras. De acordo com Silva:

Gramática de Construções e teoria da gramaticalização partilham os temas da emergência dos padrões gramaticais, da relação entre léxico e gramática e da função crucial do uso. A principal vantagem teórica da abordagem construcionista da gramaticalização é evidenciar que não pode sustentar-se a tradicional separação entre léxico e gramática, que itens lexicais e construções esquemáticas interagem de diversos modos e que os processos de gramaticalização poderão situar-se em diferentes pontos do contínuo entre léxico e gramática (SILVA, 2012, p. 6).

8 Constructionalization is the creation of formnew-meaningnew (combinations of) signs. It forms new type nodes, which have new syntax or morphology and new coded meaning in the linguistic network of a population of speakers. It is accompanied by changes in degree of schematicity, productivity, and compositionality. The constructionalization of schemas always results from a succession of micro-steps and is therefore gradual. (TRAUGOTT, TROUSDALE, 2013, p. 21-22). 
Pode-se, assim, conceber construcionalização como um processo mais abrangente, que, em termos analíticos, engloba tanto processos de gramaticalização quanto de lexicalização. Aliás, Traugott e Trousdalle (2013) propõem distinguir construcionalização gramatical (= gramaticalização) de construcionalização lexical (=lexicalização). Segundo os autores, a construcionalização gramatical é aquela em que ocorre o "desenvolvimento de morfemas individuais ('morfema gramatical'), os quais são tipicamente simples ou 'atômicos' em estrutura, e mais frequentemente, específicos ou "substantivos"” (TRAUGOTT, TROUSDALE, 2013, p. 94). Em relação à construcionalização lexical, eles afirmam que ela ocorre quando há o "desenvolvimento de novos signos que são forma $_{\text {nova }}$ - significado $_{\text {novo }}$ e no qual o polo do significado está associado principalmente com uma semântica concreta e o polo da forma, com categorias principais, como N, V ou Adj" ${ }^{10}$ (TRAUGOTT, TROUSDALE, 2013, p. 149).

Outra vantagem que se pode apontar na adoção da abordagem da construcionalização para descrever processos de mudança linguística, como se faz neste trabalho, é a possibilidade de se captar, conjuntamente, fatores formais e funcionais envolvidos na mudança. Conforme ilustra o esquema a seguir, representativo do conceito de construção dado em Croft (2001), esses fatores são os que sustentam o link de relação simbólica entre forma (propriedades sintáticas, morfológicas e fonológicas) e função (propriedades semânticas, pragmáticas e discursivo-funcionais) de uma construção. São, assim, esses fatores que naturalmente se alteram, em maior ou menor grau, conforme a mudança ocorre.

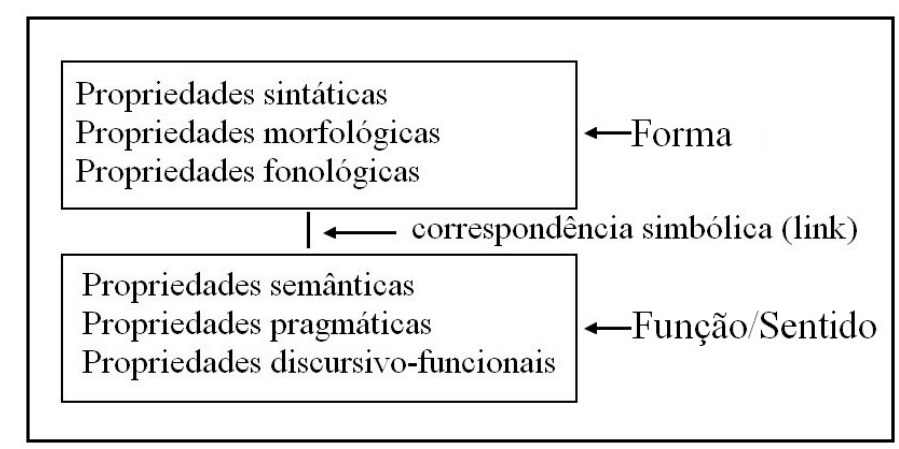

Figura 1: Modelo de representação simbólica da construção (CROFT, 2001, p. 18)

9 Development of individual morphemes ('grams'), which are typically simple or 'atomic' in structure, and more often than not, specific or 'substantive' (TRAUGOTT, TROUSDALE, 2013, p. 94).

10 Development of new sigs which are formnew-meaningnew and in which the meaning pole is associated mainly with concrete semantics and the form pole with major categories such as N, V, or ADJ (TRAUGOTT, TROUSDALE, 2013, p. 149). 


\section{Graus de construcionalização de ((n)a) hora (em) que}

Para a análise, nesta seção, dos graus de construcionalização de ((n)a) hora (em) que, baseamonos na proposta de Traugott $(2008,2012)$ e Traugott e Trousdale (2013), segundo a qual o maior e menor grau de construcionalização de uma forma pode ser descrito a partir de sua composicionalidade, produtividade e esquematicidade. Os dois primeiros fatores serão discutidos nesta seção, ao passo que os graus de esquematicidade de ((n)a) hora (em) que serão objeto da seção 4.

Conforme referido anteriormente, a composicionalidade, de acordo com Traugott e Trousdale (2013), é um fator ligado à transparência entre a forma e a função da construção considerando-se a integração entre seus itens. Se uma construção tem maior grau de composicionalidade, um falante compreende o significado dos itens da construção individualmente, o que não ocorre se a construção apresentar baixa composicionalidade. Nesse caso, o falante compreenderá apenas o significado global da construção, e haverá, portanto, uma menor transparência semântica entre a combinação do significado das partes e a forma/sintaxe da construção (TRAUGOTT, TROUSDALE, 2013).

Em relação ao grau de composicionalidade das formas de ((n)a) hora (em) que, pode-se verificar, a partir da ocorrência em (2), reapresentada abaixo como (5), o alto grau de abstratização semântica do significado do nome hora, quando integra a unidade na hora que.

(5) você pega a goiabada você derrete um pedaço dela... com um po(u)co de água... $\underline{n a}$ hora que ela fica bem cremosa dura... você pega esse creme branco e mistura com a... calda... da goiabada (IBORUNA-AC-106)

Há, no exemplo em (5), a indicação de um momento por meio da construção na hora que. A oração [ela fica bem cremosa dura] é utilizada como referência para o momento em que se pega esse creme branco e mistura com a calda da goiabada. Existe nessa relação entre as orações um significado temporal, assim como no nome hora; no entanto, esse significado é estabelecido pela construção como um todo; hora aparece com seu significado esmaecido e está amalgamado aos demais itens da construção. Conforme a proposta apresentada por Traugott e Trousdale (2013), há uma diminuição semântica em cada item, incluindo o nome hora, o que faz com que o significado da construção só seja possível de ser compreendido quando interpretado a partir de seu todo, no qual os itens atuam em uma mesma unidade linguística.

Para evidenciar o grau de composicionalidade presente em cada uma das formas de ((n)a) 
hora (em) que, propomos a aplicação de um teste, por meio do qual se insere, no interior da unidade linguística, o modificador exata. Se com a inserção desse adjetivo a locução se tornar natural, essa será uma evidência de que há um maior grau de composicionalidade na forma da construção, permitindo que haja inserção de elementos em seu interior. Caso a ocorrência do modificador dentro da construção resulte em uma forma pouco natural ao falante de português, haverá menor grau de composicionalidade na forma, com indicação de uma maior aglutinação entre os itens e reanálise dos elementos na formação da locução conjuntiva. Tomando a ocorrência em (5) como exemplo, pode-se verificar como esse teste se aplica à forma mais completa e às formais mais reduzidas de ((n)a) hora (em) que.

(6a) na hora exata em que ela fica bem cremosa dura... você pega esse creme branco e mistura com a... calda... da goiabada.

(6b) ? na hora exata que ela fica bem cremosa dura... você pega esse creme branco e mistura com a... calda... da goiabada.

(6c) ? a hora exata que ela fica bem cremosa dura... você pega esse creme branco e mistura com a... calda... da goiabada.

(6d) * hora exata que ela fica bem cremosa dura... você pega esse creme branco e mistura com a... calda... da goiabada.

O teste revela que a forma mais completa da locução, em (6a), admite com bastante naturalidade a presença de um modificador ao lado do nome hora, um forte indício de seu baixo grau de composicionalidade e, assim, de sua natureza construcional. As formas intermediárias, na hora que e a hora que, apresentam gradualmente menor naturalidade na presença do modificador exata. Em ambos os casos, apesar de ser possível que um falante faça uso da sequência com o modificador, parece haver certo truncamento na pronúncia da construção, o que possivelmente interfere em sua naturalidade. Já hora que, parece possuir seus itens mais integrados uns aos outros e, portanto, com baixo grau de composicionalidade, atestado pela pouca naturalidade da construção com a presença de um modificador do nome hora. Em comparação à forma analisada anteriormente (a hora que), a presença de exata nesse caso parece aumentar o truncamento na pronúncia da construção, contribuindo para o seu estranhamento a um falante nativo.

A partir desta análise da composicionalidade das formas de ((n)a) hora (em) que, comprovada por um conjunto significativo de dados da pesquisa (295 ocorrências no total), pode-se propor o seguinte 
cline de construcionalização das formas. Quanto mais à direita do cline, maior é o amalgamento entre os itens que compõem a construção e, assim, maior será o grau de construcionalização das formas.

na hora em que > na hora que > a hora que > hora que

\section{Figura 2: Cline de construcionalização de ((n)a) hora (em) que}

O amalgamento entre os itens na construção, impulsionado por sua baixa composicionalidade, também pode ser entendido como um processo de chunking, nos termos de Bybee (2010). Segundo a autora:

chunking é o processo por trás da formação e do uso de fórmulas ou de sequências préfabricadas de palavras como take a break, break a habit, pick and choose e é um mecanismo primário que conduz à formação de construções e estrutura de constituinte ${ }^{11}$ (BYBEE, 2010, p. 35).

Pode-se considerar, desse modo, que o processo cognitivo de chunking atua na construcionalização das formas de ((n)a) hora (em) que, em conjunto com a diminuição da composicionalidade de seus itens.

Com a disposição das formas de ((n)a) hora (em) que no cline proposto, observa-se que há uma correlação entre o grau de composicionalidade e a redução fonológica das formas da construção. A redução fonológica, que está, portanto, intimamente ligada ao grau de composicionalidade, é um processo que pode atingir a construção em seu processo de construcionalização gramatical, tal como o faz o conhecido processo de erosão fonológica em casos de gramaticalização (LEHMANN, 1982).

No caso das diferentes formas de ((n)a) hora (em) que, com a redução fonológica que envolve o apagamento da preposição em, antes e depois do nome hora, e do determinante $a$, elas passam cada vez mais a ser interpretadas como uma locução conjuntiva, e menos como um sintagma nominal determinado e modificado por uma oração relativa. Nesse sentido, hora que, que apresenta maior grau de redução fonológica e tem seus itens mais integrados uns aos outros, corresponde à forma menos composicional e, também, à forma mais esquemática da construção, por apresentar maior grau de abstração (dessemanticização) de seus itens componentes.

O cline de construcionalização de ((n)a) hora (em) que proposto aqui encontra correspondência

11 Chunking is the process behind the formation and use of formulaic or prefabricated sequences of words such as take a break, break a habit, pick and choose and it is also the primary mechanism leading to the formation of constructions and constituent structure (BYBEE, 2010, p. 35). 
parcial com o segundo fator de construcionalização proposto por Traugott e Trousdale (2013): a produtividade da construção.

No corpus investigado, foram encontradas 295 ocorrências de ((n)a) hora (em) que, que se dividiram em 1 ocorrência $(0,5 \%)$ de na hora em que, 84 ocorrências de na hora que (28,5\%), 168 de a hora que (57\%) e 42 ocorrências (14\%) de hora que. A única ocorrência da forma na hora em que encontrada no corpus é a que apresentamos em (1), anteriormente neste texto. As ocorrências em (7) a (9), a seguir, são ilustrativas das três formas mais reduzidas da construção presentes no corpus.

(7) e ele foi embora pra essa festa tal... aí ele foi... de boa chegô(u) lá... foi na festa tudo tal aí na hora que ele tava voltan(d)o... ele... deu de frente c'um boi no meio da avenida $d a /$ da rodovia ... e aí... tal capotô(u) o carro (IBORUNA-AC-019)

(8) depois que tava tudo refogado aí colocava... ÉH:: legumes à gosto né? [Doc.: aham ((concordando))] cê coloca e o de s/ o trivial cebo::la... éh:: Alho né? ocê coloca de(i)xa (refogá(r)) e coloca cerveja a hora que tivé(r) mais ou menos... borbulhando a cerveja você coloca $a . .$. o frango né?... faz ele... ali... o arroz faz separado... (IBORUNA-AC-075)

(9) nem jogo sal nada corto um monte de pedacinho de tomate... e coloco num prato... pra pra comê(r) junto com o miojo... daí::... hora que acaba eu ti::ro... vô(u) lá:: na pia porque eu gosto de deixá(r) um po(u)quinho de água (IBORUNA-AC-010)

No tocante à produtividade, Traugott e Trousdale (2013) consideram que se trata de um fator ligado às frequências type (unidade particular) e token (número de ocorrências) (BYBEE, 2003). Assim, conforme a proposta de Bybee (2003), em processos de mudança como a construcionalização, a frequência type e token impulsiona, ou refreia, o surgimento de novas formas.

Para a construção em estudo, a expectativa era a de que a forma mais avançada no processo de construcionalização, hora que, fosse também a mais produtiva, a mais frequente entre os dados. O que ocorre, entretanto, é que a forma mais frequente no corpus é $\underline{a}$ hora que, que ainda conta com a presença do determinante $a$. Uma justificativa para a baixa produtividade de hora que pode estar relacionada justamente ao seu grau mais elevado de construcionalização, ou seja, a baixa produtividade, nesse caso, pode ser resultado da natureza inovadora da construção no sistema gramatical, portanto, em um estágio ainda incipiente de mudança em comparação às outras formas, como a forma a hora que, que se mostra mais produtiva.

De modo mais geral, é possível depreender desse comportamento que a correlação entre a 
esquematicidade e a composicionalidade das formas, por um lado, e a produtividade, por outro, dependem não só do grau de construcionalização de uma forma, mas também de seu estágio de mudança no sistema linguístico, em relação a formas semelhantes. Por essa razão, em uma perspectiva sincrônica, nem sempre a forma com alto grau de construcionalização (esquematicidade alta e composicionalidade baixa) será necessariamente a mais produtiva em um recorte temporal da língua que se toma para análise.

\section{Hierarquia construcional na mudança de locuções conjuntivas}

$\mathrm{Na}$ seção anterior, foram analisados os graus de composicionalidade e produtividade da construção ((n)a) hora (em) que. Nesta seção, propomos uma discussão do grau de esquematicidade das formas, conforme propõem Traugott e Trousdale (2013).

De acordo com os autores, o grau de esquematicidade "é uma propriedade de categorização que crucialmente envolve abstração" (TRAUGOTT; TROUSDALE, 2013, p. 13). Dessa forma, a esquematicidade, segundo Traugott $(2008,2012)$, tem relação com níveis de estruturação que se caracterizam por graus distintos de abstração e generalização, pelos quais passa um item alvo de construcionalização. Esses níveis são, em ordem crescente de abstração, o nível dos construtos, o de microconstruções, o de mesoconstruções e, por fim, o de macroconstruções, como definidos a seguir, em trecho extraído de Traugott (2008):

\footnotetext{
- macroconstruções: pareamentos de forma-significado que são definidos pela estrutura e pela função, como, por exemplo, partitivo, construção modificadora de grau, etc,

- mesoconstruções: conjuntos de construções específicas de comportamento similar,

- microconstruções: tipos de construção individuais,

- construtos: ocorrências empiricamente atestadas, que são o locus da mudança.
}

(TRAUGOTT, 2008, p. 236)

As macro e mesoconstruções refletem os níveis abstratos da hierarquia construcional. Enquanto a macroconstrução é o nível mais alto, em que está presente a representação abstrata e mais genérica das construções, a mesoconstrução reúne construções abstratas similares e, portanto, mais específicas do que as macroconstruções. As mudanças que ocorrem nesses níveis, segundo Traugott (2008), são observadas com mais vagar em uma distância temporal maior, quando é o caso, e a partir de uma grande quantidade de dados. 
Os dados de ((n)a) hora (em) que, objetos desta pesquisa, foram analisados em relação ao comportamento de fatores de diferentes tipos, tanto formais (morfológicos e sintáticos) quanto funcionais (semânticos e pragmáticos). As propriedades características da forma abstrata, porém específica, da construção (a mesoconstrução [(prep) (art) $\mathrm{N}_{\text {TEMPORAL }}$ (prep) que]) encontram-se esquematizadas no quadro a seguir. Elas podem ser vistas como as que constituem o pareamento forma-função da mesoconstrução na hora que, isto é, as propriedades formais e funcionais que compõem as duas faces dessa construção, conforme a acepção de construção que se encontra em Croft (2001), esquematizada anteriormente na Figura 1.

\begin{tabular}{|c|c|c|}
\hline \multirow{2}{*}{ FORMA } & $\begin{array}{l}\text { Propriedade } \\
\text { Morfológica }\end{array}$ & $\begin{array}{l}\text { - Ocorrência em sentenças com sujeitos } \\
\text { não idênticos } \\
\text { • Correlação modo-temporal no presente } \\
\text { do Indicativo nas orações da sentença }\end{array}$ \\
\hline & Propriedade Sintática & $\begin{array}{l}\text { - Introdução de orações hipotáticas } \\
\text { antepostas }\end{array}$ \\
\hline \multirow[t]{2}{*}{ FUNÇÃO } & Propriedade Semântica & $\begin{array}{l}\text { - Valor circunstancial temporal } \\
\text { - Localização temporal majoritariamente } \\
\text { no passado } \\
\text { - Eventos da oração hipotática pontuais }\end{array}$ \\
\hline & $\begin{array}{l}\text { Propriedade Pragmático- } \\
\text { discursiva }\end{array}$ & $\begin{array}{l}\text { - Ocorrência majoritária em textos do tipo } \\
\text { narrativa de experiência. }\end{array}$ \\
\hline
\end{tabular}

Quadro 1: Pareamento forma-função de ((n)a) hora (em) que

A partir dos mesmos fatores formais e funcionais, foram analisadas as diferentes formas de ((n) a) hora que. Os resultados revelam principalmente uma tendência à especialização da forma mais reduzida hora que, o que também atesta seu maior grau de construcionalização em comparação às demais. As propriedades características de cada uma das formas da construção estão sintetizadas no quadro a seguir. 


\begin{tabular}{|c|c|c|c|}
\hline Fatores & Na hora que & Ahora que & Hora que \\
\hline Posição da oração & Anteposta & Anteposta & Anteposta \\
\hline Corref. entre sujeitos & Não idênticos & Não idênticos & Não idênticos \\
\hline Correl. modo-temporal & Pres. Ind./Pres. Ind. & Pres. Ind./Pres. Ind. & Pres. Ind./Pres. Ind. \\
\hline Valor circunstancial & Tempo & Tempo & Tempo \\
\hline Localização temporal & Passado & Passado & Presente \\
\hline Pontualidade do evento & Pontual & Pontual & Pontual \\
\hline Tipo de texto & Nar. de experiência & Nar. de experiência & Rel. de procedimento \\
\hline
\end{tabular}

Quadro 2: Comparação entre as formas de ((n)a) hora que

Observa-se que os fatores localização temporal e tipo de texto distinguem a forma mais reduzida hora que das demais formas da locução. Essas seriam, portanto, as propriedades que, conforme se considera neste trabalho, mostram-se relevantes para a mudança construcional da forma, isto é, elas responderiam pelos passos que caracterizam o percurso de construcionalização do item.

A partir desses resultados, propomos a seguinte hierarquia construcional para ((n)a) hora (em) que.

\begin{tabular}{|c|c|}
\hline Nível & Construção \\
\hline Macroconstrução & {$\left[\mathrm{N}_{\text {CIRCUNSTANCIAL }} q u e\right]_{\text {CONECTIVo }}$} \\
\hline Mesoconstrução & $\begin{array}{c}{\left[\left(\text { prep) (art) } \mathrm{N}_{\text {TEMPORAL }} \text { (prep) que }\right]\right.} \\
\left.\text { ([(prep) (art) } N_{\text {PROPORCIONAL }} \text { (prep) que }\right],\left[\left(\text { prep) (art) } N_{\text {CAUSAL }}\right.\right. \\
\text { (prep) que..) }\end{array}$ \\
\hline Microconstrução & $\begin{array}{c}{[((\mathrm{n}) \mathrm{a}) \text { hora }(\mathrm{em}) \text { que }]} \\
([((n) \text { o) dia }(\text { em) que }],[((n) \text { a) medida }(\text { em }) \text { que }],[(\text { por }) \text { causa } \\
\text { que }] \ldots)\end{array}$ \\
\hline Construto & $\begin{array}{c}\text { na hora em que, na hora que, a hora que, hora que } \\
\text { (no dia em que, no dia que, o dia que, dia que; na medida em } \\
\text { que, na medida que, a medida que, medida que, por causa que, } \\
\text { causa que...) }\end{array}$ \\
\hline
\end{tabular}

Quadro 3: Níveis hierárquicos da construção ((n)a) hora (em) que 
A macroconstrução corresponde à representação simbólica abstrata da forma mais reduzida, e mais avançada no processo de construcionalização, hora que, formada pelo Nome ${ }_{\text {TEMPORAL }}$ hora + que. No esquema, aparece um tipo mais genérico de Nome, o circunstancial, porque estamos hipotetizando que o esquema proposto retrate a construcionalização de locuções conjuntivas com outros valores circunstanciais em português, como proporção (((n)a) medida (em) que), causa, explicação ((por) causa que, (uma) vez que), etc. Para esse último tipo, parece haver já alguma evidência no português contemporâneo, como mostram as seguintes ocorrências, extraídas, respectivamente, de uma prova de Língua Portuguesa de um vestibular nacional, ocorrido em 2016, e de um romance, datado de $1993 . .^{12}$

(10) Verifica-se a ocorrência de perguntas retóricas nas tiras, pois em ambas a mãe pergunta ao filho o que ele está fazendo, na intenção de chamar sua atenção e lhe dar uma bronca, sem o intuito de receber uma resposta sobre o que ele está fazendo, vez que ela já sabe o que o filho está fazendo ao olhar para ele.

(11) "O serviço que eles fizeram no Lourival e no Chicão foi trabalho de matador profissional", pensava, quando Juventino gritou do fundo do depósito: - Tá na hora, pessoal. Amanhã eu quero ocêis tudo aqui bem cedo, causa que, dispois do armoço, nóis vamo dispachá uma partida de castanha pra Marabá."

No nível da mesoconstrução, em que ainda há uma representação abstrata, a indicação temporal já aparece ao lado do nome. Há, assim, um esquema que se concretizará na forma de types conectivos temporais, provavelmente ao lado de outros types indicativos de proporcionalidade, condicionalidade, causalidade, etc. Relacionadas à mesoconstrução específica temporal, no nível da microconstrução, estão, além de na hora que, as formas ligadas a ((n)o) dia (em) que, bem como as construções conectivas indicativas de outras circunstâncias. No nível do construto, por fim, aparecem as realizações da construção [ $\mathrm{N}_{\text {Circunstancial }}$ que $]_{\text {CONECTIVO }}$, suas ocorrências reais, ou tokens, nos termos de Bybee (2003). Evidentemente, a validade do esquema proposto às outras formas conjuncionais, apenas hipotetizada aqui, bem como a natureza macro da construção $\left[\mathrm{N}_{\text {CIRCUNSTANCIAL }} \text { que }\right]_{\text {CONECTIVo, }}$, necessita ser atestada por outros estudos, tanto sincrônicos quanto diacrônicos.

\section{Conclusões}

Neste trabalho, propusemos descrever aspectos relativos à mudança construcional e à construcionalização da locução conjuntiva $((n)$ a) hora em que do português. A partir das propostas

12 O trecho do romance citado integra o Corpus do Português (DAVIES; FERREIRA, 2006), disponível em http://www.corpusdoportugues.org. 
de Traugott (2012) e Traugott e Trousdale (2013), demonstramos que, no português falado, a locução apresenta graus variados de composicionalidade, produtividade e esquematicidade. Esses diferentes graus tanto caracterizam a mudança construcional por que passa o item, quanto permitem mapear uma possível trajetória de construcionalização da forma.

Os resultados revelam que, em termos formais, as principais mudanças que afetam $((n) a)$ hora (em) que são: a alta integração entre os elementos hora e que, que impede a modificação do nome por um sintagma adjetivo; e a redução fonológica, resultante do apagamento da preposição em e do artigo $a$, na forma mais construcionalizada hora que. Em termos de significado, ocorre especialização da forma na expressão de eventos pontuais, situados no presente, em textos do tipo relatos de procedimento, de caráter mais descritivo.

Com base nesses resultados, elaboramos uma hierarquia construcional que retrataria as mudanças envolvidas e, possivelmente, a trajetória de construcionalização de na hora que e de construções conectivas semelhantes, como na medida que, por causa que, uma vez que. Consideramos, nesta etapa da pesquisa, que a macro construção que licencia essas formas, nucleadas por Nome substantivo, seja $\left[\mathrm{N}_{\text {Circunstancial }} \text { que }\right]_{\text {Conectivo }}$. Em estudo futuro, entretanto, pretendemos investigar também a possibilidade de essa macroconstrução constituir, na verdade, um nó mais baixo em uma rede de construções que teria como macroconstrução mais alta $[\mathrm{Xque}]_{\text {conec. }}$ Essa construção foi proposta por Cezario, Silva e Santos (2015), a partir do estudo de locuções com os advérbios logo, ainda e sempre. Apesar de essa macroconstrução envolver um item circunstancial de categoria distinta (advérbios), pode bem ser que ela seja mais antiga no sistema do português e represente um nó mais alto da rede, ao qual $\left[\mathrm{N}_{\text {CIRCUNSTANCIAL }} \text { que }\right]_{\text {CONECTIVO }}$ se ligue radialmente, em uma mesma família de construções.

\section{REFERÊNCIAS}

BYBEE, J. (2010). Language, usage and cognition. New York: Cambridge University Press. (2003). Mecanismos de mudanças em gramaticalização: o papel da frequência. In: JANDA, R.; BRIAN, J. (eds.) Handbook of historical linguistics. Oxford: Blackwell. p. 602-623.

CEZARIO, M. M.; SILVA, T. S.; SANTOS, M. (2015). Formação da construção [Xque $]_{\text {conec }}$ no português. E-scrita (Revista do Curso de Letras da UNIABEU-Nilópolis), v. 6, n. 3, 229-243. 
CEZARIO, M. M.; FURTADO DA CUNHA, M. A. (Orgs.). (2013). Linguística Centrada no Uso: uma homenagem a Mário Martelotta. Rio de Janeiro: Mauad/FAPERJ.

CROFT, W. (2001). Radical Construction Grammar: syntactic theory in typological perspective. Oxford: Oxford University Press.

. (2007). Construction Grammar. In: GEERAERTS, D.; CUYCKENS, H. (ed.). The Oxford handbook of Cognitive Linguistics. New York: Oxford University Press. p. 464-508.

FUMAUX, N. C. A.; ALONSO, K. S. B.; CEZARIO, M. M. C. (2017). Construcionalização de um monte de SN: uma abordagem centrada no uso. Percursos Linguísticos, v. 7, 139-158.

FURTADO DA CUNHA, M. A. (2013). Polissemia construcional e convencionalização: o caso da construção ditransitiva. Revista do GEL, v. 10, 77-99.

.; BISPO, E. B. (2013). Pressupostos teórico-metodológicos e categorias analíticas da Linguística Funcional Centrada no Uso. Revista do GELNE, v. 15, 49-74.

FURTADO DA CUNHA, M. A.; SILVA, J. R.; BISPO, E. B. (2016). O pareamento forma-função nas construções: questões teóricas e operacionais. Revista Linguística, v. 12 (especial), p. 55-67.

GARCIA, D. M. Mudança construcional de "na hora que”: uma abordagem cognitivo-funcional. 2017. 125f. Dissertação (Mestrado em Estudos Linguísticos) - Instituto de Biociências, Letras e Ciências Exatas, Universidade Estadual Paulista Júlio de Mesquita Filho, São José do Rio Preto, 2017.

GOLDBERG, A. E. (2006). Constructions at work: the nature of generalization in language. Oxford: Oxford University Press.

(1995). Constructions: a construction grammar approach to argument structure. Chicago: University of Chicago Press.

HOPPER, P. J.; TRAUGOTT, E. (1993). Grammaticalization. Cambridge: Cambridge University Press. 
LEHMANN, C. (1982). Grammaticalization: variation synchronic and diachronic change. Lingua e Stile, v. 20, n. 3, 303-318.

MEILlET, A. (1948a). Le renouvellement des conjonctions. In: MEILLET, A. Linguistique Historique et Linguistique Générale. Paris: Champion. p.159-174.

(1948b). L'évolution des formes grammaticales. In: MEILLET, A. Linguistique Historique et Linguistique Générale. Paris: Champion, p.130-148.

MIRANDA, N. S.; SALOMÃO, M. M. M. (Org.). (2009). Construções do português do Brasil: da gramática ao discurso. Belo Horizonte: Editora UFMG.

OLIVEIRA, M. R.; ROSARIO, I. C. (Org.). (2015). Linguística centrada no uso: teoria e método. Rio de Janeiro: Lamparina, FAPERJ.

PEREIRA, M. H.; BRAGA, M. L.; PAIVA, M. C. (2010). Gramaticalização das construções (Prep) $+($ Det $)+\mathrm{N}+($ Prep $)+$ que. In: VITRAL, L.; COELHO, S. Estudos de processos de gramaticalização em português: metodologias e aplicações. Campinas: Mercado de Letras. p. 173-200.

PINHEIRO, D.; FERRARI, L. V. (2015a). Interface sintaxe-semântica: em defesa de uma abordagem construcionista para a ordem VS do português brasileiro. Letrônica, v. 8, 285-303.

(2015b). Entre a gramática de construções e a semântica lexical: em busca de uma explicação cognitivista para a distribuição dos verbos "aparecer", "surgir" e "chegar" no português brasileiro. Guavira Letras, v. 21, 14-35.

ROSARIO, I. C.; OLIVEIRA, M. R. (2016). Funcionalismo e abordagem construcional da gramática. Alfa, v. 60, n. 2, 233-259.

SALOMÃO, M. M. M. (2002). Gramática das construções: a questão da integração entre sintaxe e léxico. Veredas, Juiz de Fora, v. 6, n. 1, 63-74.

SILVA, A. S. (2012). Gramaticalização, reanálise e subjectificação. Para uma revisão do conceito de gramaticalização. In: SANTIAGO-ALMEIDA, M. M.; LIMA-HERNANDES, M. C. (Orgs.). 
História do Português Paulista. Série Estudos vol. III. Campinas/São Paulo: UNICAMP. Disponível em: <https://www.researchgate.net/publication/290789590>. Acesso em: 20 jul. 2016.

TRAUGOTT, E. C. (2012). Toward a coherent account of grammatical constructionalization. To appear in: Smirnova, E.; Barðdal, J.; Gildea, S.; Sommerer, L. (ed.). Historical Construction Grammar. Disponível em: http://pt.scribd.com/doc/150342997/Traugott-2012. Acesso em: 25 mar. 2013.

. (2008). Grammaticalization, constructions and the incremental development of language: Suggestions from the development of degree modifiers in English. In: ECKARDT, R.; JÄGER G.; VEENSTRA, T. (eds.). Variation, Selection, Development--Probing the Evolutionary Model of Language Change. Berlin/New York: Mouton de Gruyter. p. 219-250.

TRAUGOTT, E. C.; TROUSDALE, G. (2013). Constructionalization and Constructional Changes. Oxford: Oxford University Press. 